\title{
Design Considerations for Industrial Rear Passivated Solar Cells
}

\author{
Thomas Lauermann, Benjamin Fröhlich, Giso Hahn, Barbara Terheiden \\ University of Konstanz, Department of Physics, 78457 Konstanz, Germany
}

\begin{abstract}
In this work, the solar cell development issues arising by adding a dielectric rear side passivation to a standard screen-printing process are discussed with deposited $\mathrm{Al}_{2} \mathrm{O}_{3}$ on ptype $\mathrm{Cz}-\mathrm{Si}$ as an example. The influence of several design parameters is assessed in simulation and experiment and an optimization strategy is presented. These parameters include optical properties of the cell, like the choice of dielectric layer thickness and wafer surface roughness, parameters that influence the passivation quality like the temperature of the co-firing step in a belt furnace as well as electrical parameters like contact geometry, contact spacing and base resistivity. Their influence on the three efficiency-determining quantities, $V_{\mathrm{OC}}, j_{\mathrm{SC}}$ and $\mathrm{FF}$ is outlined. Special attention is paid to minimizing the inevitable loss in FF in a PERC design.
\end{abstract}

Index Terms - dielectric films, finite element methods, photovoltaic cells, semiconductor device manufacture, silicon.

\section{INTRODUCTION}

In recent years, dielectric rear side passivation of crystalline silicon solar cells has expanded from small lab-scale cells to industrial production on $156 \mathrm{~mm}$ wafers. Most development efforts are geared towards an evolutionary approach, where the prevailing metallization by means of screen printing and co-firing of thick film paste is retained and the deposition and structuring of the dielectrics is merely added into an already established process [1]-[4].

Though only a few steps are inserted, they not only introduce additional parameters. It is also observed that choices like base resistivity beneficial for homogeneous solar cells prove to be suboptimal for locally contacted cells. In this work we take a look at the parameter range of four aspects: the enhanced internal reflection at the rear contributing to a larger $\mathrm{j}_{\mathrm{SC}}$ (short circuit current density), the thermal load during contact firing that affects the passivation quality of the dielectric layer, the shape of the contacts and their passivation, both contributing to an elevated $\mathrm{V}_{\mathrm{OC}}$ (open circuit voltage), and the additional resistive effects of the base geometry resulting in an inherently lower FF (fill factor) on locally contacted solar cells.

Since the 1990s, a lot of work has been published on the geometrical optimization [5] of the so called PERC design (passivated emitter and rear cell) [6], most of it relating to small lab cells with photolithographically defined contacts. This contribution considers the dimensions and process constraints of $156 \mathrm{~mm}$ solar cells metalized with screen printing.

\section{OPTICAL OptIMIZATION OF PERC CELls}

One major advantage of using dielectric passivation instead of a full area Al back surface field is the substantial gain in short circuit current density. As can be seen from spectral response data, a major contribution of this gain stems from the enhanced reflectivity of the rear side of $90-95 \%$ at $1000 \mathrm{~nm}$ compared to $65 \%$ common for fully $\mathrm{Al}$ alloyed rear sides.

Since this effect alone leads to an increase in $\mathrm{j}_{\mathrm{SC}}$ of around $0.8 \mathrm{~mA} / \mathrm{cm}^{2}$ on screen printed $\mathrm{Si}$ solar cells capped with $80 \mathrm{~nm}$ of $\mathrm{SiN}_{\mathrm{x}}$ as shown in [2], it is worthwhile to optimize internal reflection. This is done by a raytracing simulation, executed with the software "Sunrays" [7] shown in Fig. 1. The chosen geometry is a $180 \mu \mathrm{m}$ pyramid-textured wafer with a $75 \mathrm{~nm}$ ARC (anti reflection coating) on the front side and a stack system consisting of $15 \mathrm{~nm} \mathrm{Al}_{2} \mathrm{O}_{3}(\mathrm{n}=1.76)$ plus a $\mathrm{SiN}_{\mathrm{x}}$ layer $(n=2.05)$ of variable thickness on both a flat but highly scattering as well as a specular rear side.

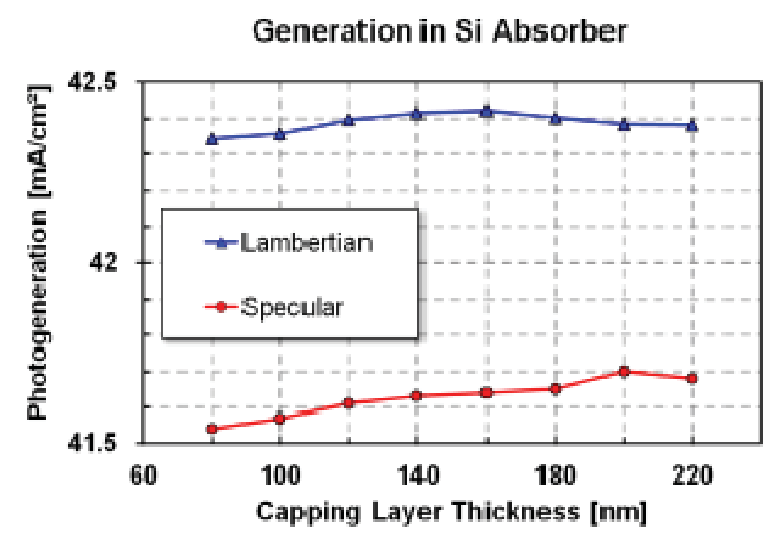

Fig. 1. Simulated photogeneration in pyramid-textured $180 \mu \mathrm{m}$ thick Si solar cell dependent on capping layer thickness $\left(\mathrm{SiN}_{\mathrm{x}}\right)$.

At $\mathrm{SiN}_{\mathrm{x}}$ thicknesses of around $160 \mathrm{~nm}$, the best internal reflectivity is achieved, around 95\%, leading to an additional gain in short circuit current density of $0.1-0.2 \mathrm{~mA} / \mathrm{cm}^{2}$ compared to $80 \mathrm{~nm}$ layer thickness, in agreement with [8]. It is worth noting that a polished, specular reflecting rear side performs worse by about $0.8 \mathrm{~mA} / \mathrm{cm}^{2}$, since most rays with normal incidence are reflected into the escape cone of the front texture at an angle of around $10.5^{\circ}$ and are coupled out symmetrically to their entrance. As can be seen in Fig. 2, isotropically scattered rays have a higher chance of additional passes through the absorber. 


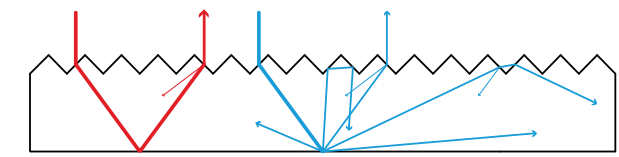

Fig. 2. Comparison of specular (red) and lambertian (blue) reflection. Many rays reflected under obtuse angles on a lambertian surface get additional passes when they hit the front texture under angles suitable for total reflection.

Therefore, the rear side has to be processed in a way that it acts as a lambertian scatterer while being as flat as possible. This is achieved in one step during chemical removal of the rear emitter and texture in an industrial inline wet bench. In our experiment, $\sim 4 \mu \mathrm{m}$ of $\mathrm{Si}$ is etched off in an acidic solution. The surface enlargement due to the texturing residues at the rear side could be lowered from $40 \%$ to $8-12 \%$, measured by optical profilometry. On solar cells from this batch the optical gain was increased from 0.8 to $1.0 \mathrm{~mA} / \mathrm{cm}^{2}$ when using a capping layer of $160 \mathrm{~nm} \mathrm{SiN}_{\mathrm{x}}$. If the rear surface enlargement is to be decreased further, an additional single sided etching process can be added after alkaline texture, it should, however, be acidic to preserve the lambertian properties of the rear side.

\section{FIRING TEMPERATURE DEPENDENCE}

A solar cell run is conducted on $125 \mathrm{~mm}$ p-type $\mathrm{Cz}-\mathrm{Si}$ material with a variation in the co-firing temperature. Wafers with $2 \Omega \mathrm{cm}$ are used, pyramid textured and a $\mathrm{POCl}_{3}$-diffused etch-back selective emitter with $30 \Omega /$ sq. contact area and $80 \Omega /$ sq. illuminated area sheet resistance is formed. They receive a direct-plasma PECVD (plasma-enhanced chemical vapor deposition) $\mathrm{ARC}$ of $\mathrm{SiN}_{\mathrm{x}}$ on the front side and $15 \mathrm{~nm}$ $\mathrm{Al}_{2} \mathrm{O}_{3}$ using $\mathrm{ALD}$ (atomic layer deposition) on the rear, capped with $80 \mathrm{~nm} \mathrm{SiN}_{\mathrm{x}}$. The cells are then inkjet structured and metalized by screen printing using commercially available pastes on front and rear side.

Firing temp. dependence of IQE

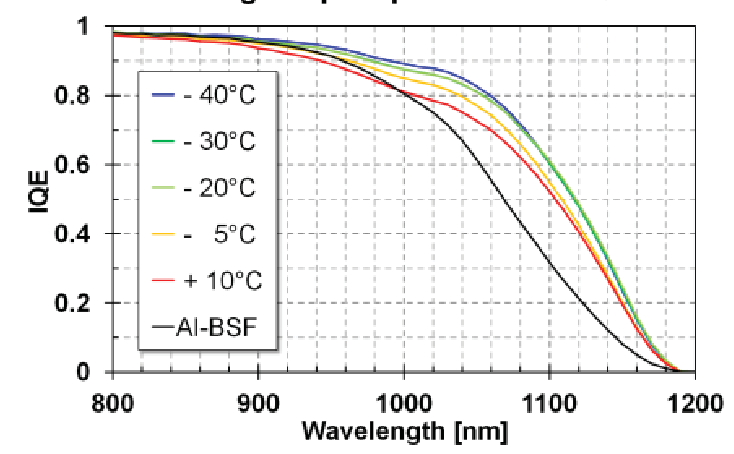

Fig. 3. Co-firing temperature dependence of long-wavelength IQE. Temperatures given are relative to standard firing conditions.
After co-firing in 5 different groups differentiated by the peak temperature, the cells are evaluated in terms of longwavelength internal quantum efficiency (IQE) and $V_{O C}$.

It can be seen from Fig. 3 that the surface recombination velocity of an $\mathrm{Al}_{2} \mathrm{O}_{3}$-passivated rear side is sensitive to heat. In the temperature range relevant for co-firing, a correlation between higher firing temperature and higher recombination velocity is found, apparent in a better long-wavelength IQE at lower firing temperatures. The highest temperature results in more recombination for the non-contacted areas than for the contacted areas.

\section{TABLE I}

OPEN CIRCUIT VOLTAGE AND REAR SIDE RECOMBINATION VELOCITIES OF THE RESPECTIVE CELLS. $S_{\text {EFF }}$ IS DETERMINED FROM IQE DATA, $S_{\text {PASS }}$ IS CALCULATED [9] UNDER THE ASSUMPTION $\mathrm{S}_{\mathrm{MET}}=500 \mathrm{cM} / \mathrm{s}$.

\begin{tabular}{|c|c|c|c|}
\hline $\begin{array}{c}\text { Firing } \\
\text { Group }\end{array}$ & $\begin{array}{c}\mathrm{V}_{\mathrm{OC}} \\
{[\mathrm{mV}]}\end{array}$ & $\begin{array}{c}\text { Rear } \mathrm{S}_{\text {eff }} \\
{[\mathrm{cm} / \mathrm{s}]}\end{array}$ & $\begin{array}{c}\mathrm{Al}_{2} \mathrm{O}_{3} \mathrm{~S}_{\text {pass }} \\
{[\mathrm{cm} / \mathrm{s}]}\end{array}$ \\
\hline$-40^{\circ} \mathrm{C}$ & 640 & 90 & 55 \\
\hline$-30^{\circ} \mathrm{C}$ & 633 & 130 & 90 \\
\hline$-20^{\circ} \mathrm{C}$ & 636 & 120 & 80 \\
\hline$-5^{\circ} \mathrm{C}$ & 629 & 380 & 350 \\
\hline$+10^{\circ} \mathrm{C}$ & 625 & 670 & 700 \\
\hline $\mathrm{Al}-\mathrm{BSF}$ & 631 & 320 & - \\
\hline
\end{tabular}

To benefit from a low rear side recombination and therewith a high $\mathrm{V}_{\mathrm{OC}}$, two optimization paths are feasible. Obviously, the firing temperature should be chosen as low as possible while still providing a reliable front contact. In our example, this is conveniently achieved by contacting highly-doped finger regions in a selective emitter structure, allowing deviations of $40^{\circ} \mathrm{C}$ from the optimal firing temperature. Additionally, the selective emitter gain synergizes with a passivated rear side [10]. Furthermore, the latest advances in Ag paste development also facilitate this goal, since the finer Ag particle composition can establish a low-resistance contact to homogeneous standard emitters over a wide range of firing temperatures.

The other option is increasing the temperature stability of the dielectric layer in terms of passivation and blistering behavior. Recent results by [11] and [12] show increased firing stability of $\mathrm{Al}_{2} \mathrm{O}_{3}$ films deposited or annealed at higher temperatures. First cells passivated using this method showed $\mathrm{V}_{\mathrm{OC}}$ values of up to $644 \mathrm{mV}$ when being fired at standard temperatures.

\section{CONTACT FORMATION AND PASSIVATION}

When the dielectrically coated rear side is sufficiently passivating, recombination at the rear contacts becomes a limiting factor. To obtain a high cell voltage it is therefore important that the rear contacts are passivated by the formation of a local back surface field (BSF). 
Local BSF formation is governed by the $\mathrm{Si}$ concentration directly above the contact site. This concentration is influenced by Si diffusion in the Al paste as measured by [13]. Achieving a sufficient $\mathrm{Si}$ saturation for BSF epitaxy is dependent on paste and firing conditions. It can be enhanced by choosing lines instead of dots to restrict diffusion to one dimension. Furthermore, Si concentration is also higher above wider contacts. In previous experiments, the most beneficial opening structures were lines with minimum width of $90 \mu \mathrm{m}$ [14]. This sets the metallization fraction of the rear side to 5$10 \%$ and thereby constrains the feasible pitch values on industrial PERC cells in the $1 \mathrm{~mm}$ range as opposed to the optimization calculations done in literature for lab-type cells with evaporated contacts [15] that can feature narrow contacts or a dot pattern with a smaller pitch and a metallization fraction of around $1 \%$. However, the metallization fraction is expected to be further minimized by applying a paste enriched with $\mathrm{Si}$ as shown by [16] which enables narrower lines.

\section{Fill Factor Issues: Choosing A SuItable LAyout}

Due to an additional lateral contribution to series resistance, all industrial PERC cells show a lower fill factor when compared to their full area contacted counterparts.

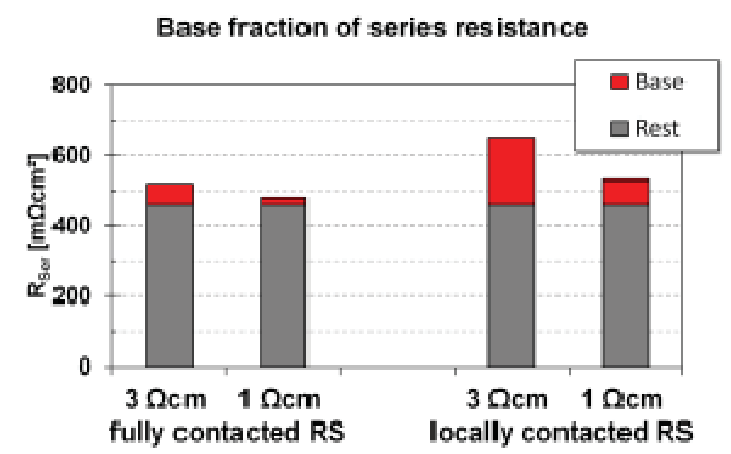

Fig. 4. Measured series resistances of solar cells manufactured on different substrates (Cz-Si, $125 \mathrm{~mm})$.

However, on several cell runs it is found that this drop is much more distinct than one would expect from the minor additional series resistance contribution from the base and the increased rear contact resistance. In our example, the FF is dropping from $79.2 \%$ to $75.2 \%$ in the $3 \Omega \mathrm{cm}$ case and from $79.4 \%$ to $77.2 \%$ in the $1 \Omega \mathrm{cm}$ case, while a small increase in $\mathrm{R}_{\text {Ser }}$ in the range of $40 \mathrm{~m} \Omega \mathrm{cm}^{2}$ or $120 \mathrm{~m} \Omega \mathrm{cm}^{2}$ (see Fig. 4) should only justify a FF loss of about 0.4 or $1 \%$ abs.

To understand the lower than expected fill factors, a series of finite element simulations is conducted with the semiconductor device simulator package Sentaurus [17] with the implementation for crystalline silicon solar cells by [18]. The rear electrode design is kept constant at a pitch of $1.2 \mathrm{~mm}$, and to account for a different amount of distributed series resistance the base resistivity is varied in a range from 0.4 to

$6 \Omega \mathrm{cm}$. The Poisson and continuity equations in the semiconductor material are solved for a unit cell consisting of a 2D cross-section including one front finger and two rear contacts on a triangular mesh consisting of approx. 25000 nodes. Profiles obtained by ECV (electrochemical capacitance-voltage) measurements are imported for the setup of front side emitter and local $\mathrm{BSF}$, so a $\mathrm{SiN}_{\mathrm{x}}$-passivated $55 \Omega /$ sq. emitter and a local BSF of $4.5 \mu \mathrm{m}$ depth can be modeled. Furthermore, ideal SRH (Shockley-Read-Hall) recombination behavior without additional injection dependence is assumed for bulk and rear side passivation. A value of $\tau_{\text {bulk }}=400 \mu \mathrm{s}$ for the bulk and conservative estimates of $S_{\text {pass }}=100 \mathrm{~cm} / \mathrm{s}$ and $Q_{\mathrm{f}}=-6 \cdot 10^{12} \mathrm{~cm}^{-2}$ for the surface recombination velocity and negative charge density of fired $\mathrm{Al}_{2} \mathrm{O}_{3}$ layers is used.

Besides extracting the cells fill factors from the simulated IV curves, the series resistance at the maximum power point (MPP) is computed using the double light method [19]. This value is used to calculate the expected FF according to the 2 diode model.

Fill Factor deviation

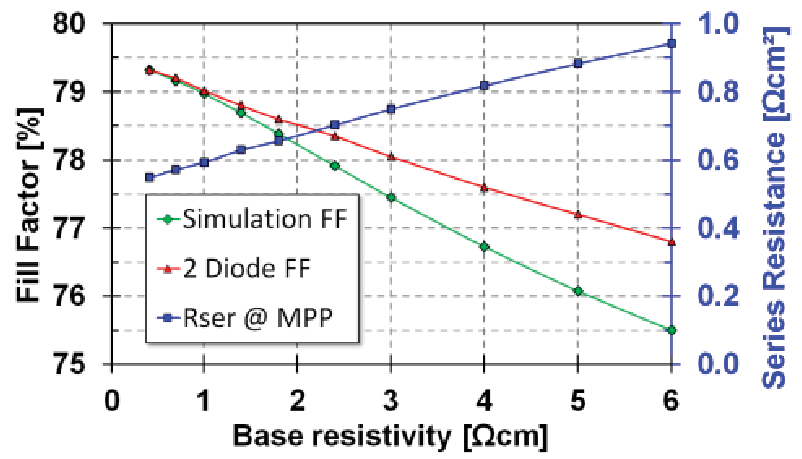

Fig. 5. Fill factor of simulated PERC cells $(1.2 \mathrm{~mm}$ rear contact pitch) with their corresponding series resistances. The theoretical fill factor resulting from a pure increase in series resistance in the 2 diode model is also given.

It can be seen in Fig. 5 that with rising series resistance, the fill factor decreases more strongly with increasing base resistivity than expected by just adding lumped series resistance. This behavior can be explained by the inhomogeneous lateral voltage distribution at MPP operation. Here, regions further away from the rear contacts operate at a higher voltage than $\mathrm{V}_{\mathrm{MPP}}$ due to the potential drop across the base resistance, supplying less current at any given voltage and thereby effectively indenting the IV curve in the region sensitive to the fill factor.

Besides the obvious optimization path of using lowerresistivity material and making the rear contact pitch sufficiently small, this behavior has another implication. Since it is the goal to keep local voltage differences across the solar cell as small as possible, the solar cell should be designed with a high degree of symmetry. This is achieved by aligning front 
grid and rear contact pattern in parallel, using integer multiples for the pitch values and matching them onto each other.

The effect of grid alignment is more pronounced on screen printed cells than on lab-type PERC cells due to the larger finger and rear contact spacing necessary, as discussed in the previous chapter. Note the 'checkered' resistance distribution on the lower cell with intentionally crossed rear-side metallization in the EL (electroluminescence) measurements shown in Fig. 6. Its yellow-red central regions indicate operation considerably off the optimal voltage and therefore a smaller area-weighed current contribution, resulting in a FF of $72.5 \%$ compared to the $74.3 \%$ of the upper cell. Besides two minor regions with imperfect contacts, the upper cell shows a more homogeneous voltage distribution, dominated by the finger resistance. This difference leads to an efficiency of $18.1 \%$ in the crossed case and $18.5 \%$ in the parallel case on $3 \Omega \mathrm{cm}$ material.
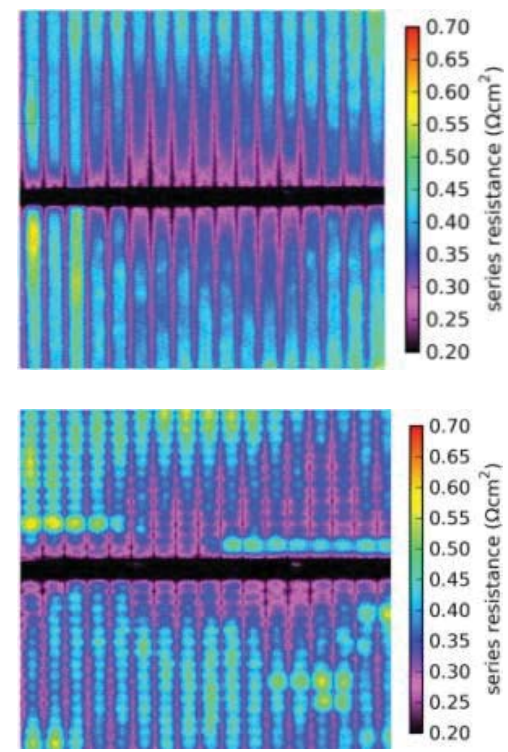

Fig. 6. EL images from otherwise comparable solar cells on $3 \Omega \mathrm{cm} \mathrm{Cz}-\mathrm{Si}$ material $(156 \mathrm{~mm}$ ) with parallel and perpendicular grid alignment.

In a following experiment, average $\mathrm{FF}$ of $79.2 \%$ are demonstrated on $1 \Omega \mathrm{cm}$ material with an optimized layout, integrating two rear contact lines per front grid finger, minimizing the lateral voltage differences across the cell further.

\section{DISCUSSION}

While layer optimization and choice of firing parameters is straightforward, the fundamental design parameters of rear contact width, pitch and base resistivity demand conflicting choices. Since metallization fraction should be minimized and the lines need a minimum width, line pitch should be maximized. A high fill factor demands low-resistance current paths. At high pitches, this can be achieved by using a low bulk resistivity material, but at the cost of increased light induced degradation (LID) [20]. Unless there is no low $\mathrm{O}_{i}$ or Ga doped material available, a compromise has to be found for p-type substrates with the additional constraint of using symmetric designs. Another option would be the permanent deactivation of the BO-complex [21].

From the reasons discussed before, analytical and 1D numerical optimization methods relying on the 2 diode model have difficulties to estimate the fill factor correctly if lateral inhomogeneities are investigated. Therefore, the 2D finite element approach used in the previous chapter is applied to solar cells with variable rear contact geometries. This is done for degradation-free material, where a $55 \Omega /$ sq. emitter contacted by a front grid with a finger distance of $2.4 \mathrm{~mm}$ on a $180 \mu \mathrm{m}$ thick $\mathrm{Si}$ wafer is chosen with base resistivity and contact pitch for the rear contact as free parameters. If LID is not taken into account, then the optimal efficiency can be achieved with a base resistivity as low as $0.7 \Omega \mathrm{cm}$ and a comparably wide spacing of two rear contacts per front grid finger.

TABLE II

INPUT PARAMETERS, CELL RESULTS AND RESULTING OUTPUT FOR DEGRADATION-FREE SUBSTRATES.

\begin{tabular}{|l|l|}
\hline Cell Dim. & $180 \mu \mathrm{m}$ thick, pyr. text. front, flat rear \\
\hline Doping & $55 \Omega / \mathrm{sq}$. emitter, local Al-BSF \\
\hline Lifetime & $\tau_{\text {bulk }} 400 \mu \mathrm{s}$, rear $\mathrm{S}_{\text {pass }} 100 \mathrm{~cm} / \mathrm{s}$ \\
\hline \hline IV Data & $38.9 \mathrm{~mA} / \mathrm{cm}^{2}, 665 \mathrm{mV}, 79.2 \% \mathrm{FF}, 20.5 \%$ \\
\hline \hline Cont. Pitch & $2.4 \mathrm{~mm}$ front, $1.2 \mathrm{~mm}$ rear \\
\hline Resistivity & $0.7 \Omega \mathrm{cm}$ \\
\hline
\end{tabular}

Implementation of the lifetime and injection behavior change due to LID into the simulation is accomplished in a similar way to Steingrube et al. [22], but with a focus on the industrial PERC design. In the LID case, the post-degradation lifetime is not fixed, but obtained by applying Bothe's empirical formula [23]:

$$
\tau_{\text {bulk }}=c_{B}^{-0.824} \cdot c_{O}^{-1.748} \cdot 7.675 \cdot 10^{45} \mu s
$$

The boron concentration $c_{B}$ is now derived from the resistivity used for the simulation and the interstitial oxygen concentration $c_{O}$ is set to $6 \cdot 10^{17} \mathrm{~cm}^{-3}$. Here, the parametrization of Altermatt et al. [18] is used to calculate individual effective lifetime maps for holes and electrons respectively, since the defect level for the BO-complex is closer to the conduction band and a correction factor [23] of 2 related to high-temperature processing is also taken into account. This approach incorporates the effect of injectiondependent lifetime and is therefore able to reproduce the lower 
fill factor seen on strongly injection-dependent material like degraded $\mathrm{Cz}-\mathrm{Si}$ wafers as reported by [24].

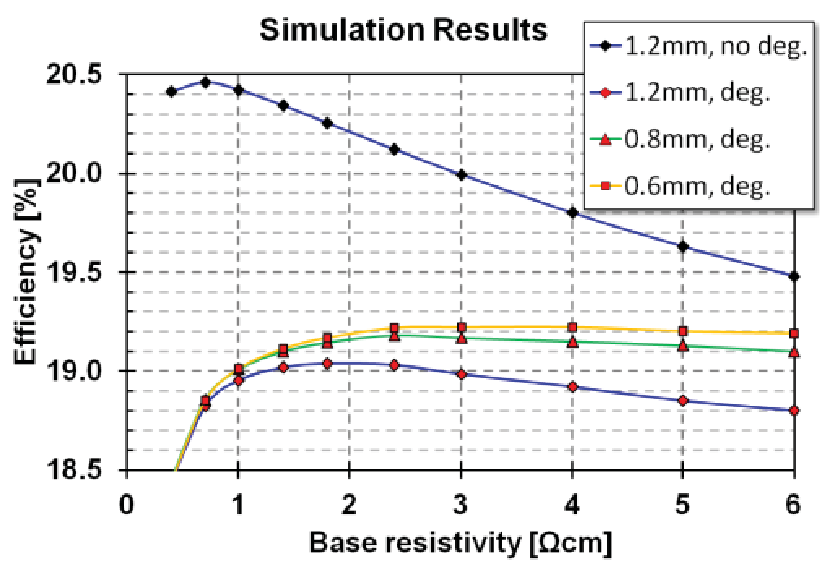

Fig. 7. Efficiency evolution with increasing series resistance for different geometries before (black) and after (red) LID.

TABLE III

INPUT PARAMETERS, CELL RESULTS AND RESULTING OUTPUT FOR OPTIMIZED EFFICIENCY AFTER COMPLETE LID.

\begin{tabular}{|l|l|}
\hline Cell Dim. & $180 \mu \mathrm{m}$ thick, pyr. text. front, flat rear \\
\hline Doping & $55 \Omega /$ sq. emitter, local Al-BSF \\
\hline Lifetime & $\tau_{\text {bulk }}(\rho)<400 \mu \mathrm{s}$, rear $\mathrm{S}_{\text {pass }} 100 \mathrm{~cm} / \mathrm{s}$ \\
\hline \hline IV Data & $38.7 \mathrm{~mA} / \mathrm{cm}^{2}, 652 \mathrm{mV}, 76.3 \% \mathrm{FF}, 19.2 \%$ \\
\hline \hline Cont. Pitch & $2.4 \mathrm{~mm}$ front, $0.6 \mathrm{~mm}$ rear \\
\hline Resistivity & $3 \Omega \mathrm{cm}$ \\
\hline
\end{tabular}

The sharp drop in cell voltage after LID shifts the optimum resistivity for the $1.2 \mathrm{~mm}$ design (blue lines) from $0.7 \Omega \mathrm{cm}$ to $1.8 \Omega \mathrm{cm}$, resulting in $19.05 \%$ efficiency. In this regime, efficiency can be enhanced furthermore by moving the contacts closer, the loss in additional contact recombination is more than offset by the higher fill factor and the higher voltage when using higher-resistivity material. Therefore, the optimal resistivity in our given example is $2.4 \Omega \mathrm{cm}$ for $0.8 \mathrm{~mm}$ pitch, yielding $19.2 \%$ and $3 \Omega \mathrm{cm}$ for $0.6 \mathrm{~mm}$ pitch, topping out at $19.25 \%$ efficiency.

\section{SUMMARY}

With dielectric rear side passivation becoming a topic of interest for industrial solar cell production, their electrical and optical properties have to be optimized in a way that is compatible with cost-effective screen printing based production methods. It is found that the rear side should be a $160 \mathrm{~nm}$ thick dielectric reflector on a lambertian surface. Besides the current increase by the passivation, an additional optical gain of $1.0 \mathrm{~mA} / \mathrm{cm}^{2}$ is measured on such solar cells. Firing temperatures should be lowered to not deteriorate the passivation by overfiring or blistering while the deposition conditions should be slightly altered to harden the layers against the high thermal budget during co-firing. For optimal local BSF formation conditions, the rear contacts should be lines with minimum $90 \mu \mathrm{m}$ width and the $\mathrm{Al}$ paste should feature an intrinsic silicon content to facilitate BSF formation.

Additionally, the cell design should be highly symmetric to avoid additional FF losses due to distributed resistances on the comparably long distances between rear contacts in the $1 \mathrm{~mm}$ range necessary for industrial PERC cells. Average fill factors of $79.2 \%$ are demonstrated on large area screen printed solar cells. The lower fill factors seen on industrial PERC cells cannot be described by means of the 2 diode model, since they originate from the increasingly complex 3D structure of the solar cells. Therefore, they are quantified by finite element simulation. It is also the basis for an efficiency optimization strategy presented here, hinting that with current technologies, efficiencies up to $20.5 \%$ are feasible on degradation-free ptype Si materials and $19.3 \%$ on fully degraded $\mathrm{Cz}-\mathrm{Si}$ material with a common oxygen content.

\section{ACKNOWLEDGEMENT}

The authors would like to thank L. Mahlstaedt, S. Ohl, B. Rettenmaier, J. Ruck, F. Mutter and C. Gründler from University of Konstanz as well as H. Haverkamp, C. Demberger, O. Meixner and I. Petrik from Gebr. Schmid $\mathrm{GmbH} \& \mathrm{Co}$. for their support during processing and characterization. The content of this publication is the responsibility of the authors. The financial support for parts of this work by the German BMU under contract FKZ 325168 and 0325079 is gratefully acknowledged.

\section{REFERENCES}

[1] G. Agostinelli, P. Choulat, H.F.W. Dekkers, S. De Wolf, G. Beaucarne, "Screen printed large area crystalline silicon solar cells on thin substrates", Proc. 20th EU PVSEC, 2005, p. 1339

[2] T. Lauermann, T. Lüder, S. Scholz, G. Hahn, B. Terheiden, "Enabling dielectric rear side passivation for industrial mass production by developing lean printing-based solar cell processes", Proc. 35th IEEE PVSC, 2010, p. 28

[3] S. Gatz, H. Hannebauer, R. Hesse, F. Werner, A. Schmidt, T Dullweber, J. Schmidt, K. Bothe, R. Brendel, "19.4\%-efficient large-area fully screen-printed silicon solar cells" Phys. Status Solidi RRL vol. 5, No. 4, 2011, p. 147

[4] L. Gautero, J. Rentsch, L. Weiss, N. Kohn, S. Eigner, M. Zimmer, J. Specht, J. Nekarda, D. Stüwe, M. Retzlaff, D. Biro, J.-M. Sallese, R. Preu, "Industrial approach for the deposition, through-vias wet opening and firing activation of a backside passivation layer applied on solar cells", Proc. 23th EU PVSEC, 2008, p. 1453

[5] A.G. Aberle, G. Heiser, M.A. Green, "Comprehensive analytical model for locally contacted rear surface passivated solar cells", J. Appl. Phys. vol. 75, 1994, p. 5391

[6] A.W. Blakers, A. Wang, A.M. Milne, J. Zhao, M.A. Green, " $24 \%$ efficient silicon solar cells", Appl. Phys. Lett. vol. 55, 1989, pp. 1363 
[7] R. Brendel, "SUNRAYS: A versatile ray tracing program for the photovoltaic community", Proc. 12th EU PVSEC, 1994, p. 1339

[8] D. Kray, M. Hermle, S.W. Glunz, Theory and experiments on the back side reflectance of silicon wafer solar cells", Prog. Photovolt.: Res. Appl vol. 16, 2008, p. 1

[9] B. Fischer, Loss analysis of crystalline silicon solar cells using photoconductance and quantum efficiency measurements, Ph.D. thesis, University of Konstanz, 2003

[10] K.A. Münzer，J. Schöne，A. Teppe，M. Hein， R.E. Schlosser, M. Hanke, J. Maier, A. Yodyunyong, J. Isenberg, T. Friess, C. Ehling, K. Varner, S. Keller, P. Fath, "Towards $19.5 \%$ industrial crystalline silicon solar cells", Proc. 26th EU PVSEC, 2011, p. 843

[11] T. Lüder, T. Lauermann, A. Zuschlag, G. Hahn, B. Terheiden, " $\mathrm{Al}_{2} \mathrm{O}_{3} / \mathrm{SiN}_{\mathrm{x}}$-stacks at increased temperatures: Avoiding blistering during contact firing", Energy Procedia, 2012, in print

[12] B. Vermang, H. Goverde, L. Tous, A. Lorenz, P. Choulat, J. Horzel, J. John, J. Poortmans, R. Mertens, "Approach for $\mathrm{Al}_{2} \mathrm{O}_{3}$ rear surface passivation of industrial p-type Si PERC above 19\%" Prog. Photovolt.: Res. Appl. vol. 20, 2012, p. 269

[13] E. Urrejola, K. Peter, H. Plagwitz, G. Schubert, "Silicon diffusion in aluminum for rear passivated solar cells", Appl. Phys. Lett. vol. 98, 2011, 153508

[14] T. Lauermann, A. Zuschlag, S. Scholz, G. Hahn, B. Terheiden, "The influence of contact geometry and sub-contact passivation on the performance of screen-printed $\mathrm{Al}_{2} \mathrm{O}_{3}$ passivated solar cells", Proc. 26th EU PVSEC, 2011, p. 1137

[15] C.R. Catchpole, A.W. Blakers, "Comprehensive analytical model for locally contacted rear surface passivated solar cells", Sol. En. Mat. vol. 73, 2002, p. 189
[16] M. Rauer, C. Schmiga, R. Woehl, K. Ru hle, M. Hermle, M. Ho rteis, D. Biro, S.W. Glunz, "Investigation of aluminumalloyed local contacts for rear surface-passivated silicon solar cells", IEEE J. Photovolt. vol. 1, 2011, p. 22

[17] Sentaurus, Synopsys Inc., Mountain View, CA, 2005

[18] P.P. Altermatt, "Models for numerical device simulations of crystalline silicon solar cells - a review", J. Comput. Electron. vol. 10, 2011, p. 314

[19] M. Wolf, H. Rauschenbach, "Series resistance effects on solar cell measurements", Adv. Energy Conv. vol. 3, 1963, p. 455

[20] H. Fischer, W. Pschunder, "Investigation of photon and thermal induced changes in silicon solar cells", Proc. 10th IEEE PVSC, 1973, p. 404

[21] A. Herguth, G. Schubert, M. Käs, G. Hahn, "Avoiding boronoxgen related degradation in highly boron-doped $\mathrm{Cz}$ silicon", Proc. 32nd IEEE PVSC, 2006, p. 530

[22] S. Steingrube, H. Wagner , H. Hannebauer, S. Gatz, R. Chen, S.T. Dunham, T. Dullweber, P.P. Altermatt, R. Brendel, "Loss analysis and improvements of industrially fabricated $\mathrm{Cz}$-Si solar cells by means of process and device simulations", Energy Procedia vol. 8, 2011 , p. 263

[23] K. Bothe, R. Sinton, J. Schmidt, "Fundamental boron-oxygenrelated carrier lifetime limit in mono- and multicrystalline silicon", Prog. Photovolt.: Res. Appl. vol. 13, 2005, p. 287

[24] J. Schmidt, A. Cuevas, S. Rein, S.W. Glunz, "Impact of lightinduced recombination centres on the current-voltage characteristic of czochralski silicon solar cells", Prog. Photovolt.: Res. Appl. vol. 9, 2001, p. 249 